\title{
PROPUESTA DE BUEN GOBIERNO CORPORATIVO PARA COOPERATIVAS ELÉCTRICAS
}

\section{PROPOSAL FOR GOOD CORPORATE GOVERNANCE FOR ELECTRICAL} COOPERATIVES

\author{
Pedro Severino-González , Álex Medina Giacomozzi y \\ José Patricio Lagos Cisterna
}

Resumen

\begin{abstract}
Las cooperativas son empresas cuya forma jurídica es relevante en las economías de todo el mundo, la cual se encuentra potenciada por la consideración de principios cooperativos de sus socios, lo que tiene una fuerte relación con la responsabilidad social, ética empresarial, gobernanza, teorías de los stakeholders, entre otros, lo que ha ocasionado la adopción de éste tipo de asociatividad para el desarrollo de un negocio de todo tipo, particularmente en el sector eléctrico chileno, despertando el interés de los núcleos de investigación de diversas casas de estudios superiores. Es por ello que esta investigación pretende entregar una propuesta de buen gobierno corporativo para las cooperativas eléctricas en Chile. La propuesta es una herramienta de autoaplicación, validada a través de la consulta sistemática a grupos de expertos, obteniendo como resultado un cuestionario que posee 73 reactivos expresados en afirmaciones agrupados en 22 dimensiones, con lo cual se llegó a establecer una propuesta de buen gobierno cooperativo para cooperativas eléctricas.
\end{abstract}

Palabras Claves: Gobierno Corporativo; Cooperativismo; Responsabilidad Social Empresarial; Economía Solidaria; Sustentabilidad.

\footnotetext{
${ }^{1}$ Magíster en Dirección de Empresas. Ingeniero Comercial. Licenciado en Ciencias Administrativas. Académico. Departamento de Economía y Administración Facultad de Ciencias Sociales y Económicas. Universidad Católica del Maule. E-mail: pseverino@ucm.cl

${ }^{2}$ Doctor en Finanzas y Contabilidad. Magíster en Administración y Dirección de Empresas. Contador Público y Auditor. Académico. Departamento de Gestión Empresarial. Facultad de Ciencias Empresariales. Universidad del Bío-Bío. E-mail: alex@ubiobio.cl

${ }^{3}$ Magíster (c) en Dirección de Empresas. Contador Público y Auditor. Ingeniero Comercial. Profesor de tiempo parcial. Gerente General Empresas Copelec. E-mail: patriciolagosci@gmail.com
} 
Abstract

\begin{abstract}
Cooperatives are companies whose legal form is relevant in economies all over the world, which is enhanced by the consideration of cooperative principles of their partners, which has a strong relationship with social responsibility, business ethics, governance, theories of Stakeholders, among others, which has led to the adoption of this type of partnership for the development of a business of all kinds, particularly in the Chilean electricity sector, arousing the interest of research centers in various houses of higher education. Therefore, this research intends to deliver a proposal of good corporate governance for the electric cooperatives in Chile. The proposal is a tool for self-application, validated through systematic consultation to groups of experts, resulting in a questionnaire that has 73 reagents expressed in statements grouped in 22 dimensions, which resulted in establishing a proposal for good cooperative governance for electric cooperatives.
\end{abstract}

Keywords: Corporate Governance; Cooperatives; Corporate Social Responsibility; Solidarity Economy, Sustainability.

\title{
Introducción
}

La necesidad de disponer de un gobierno corporativo sólido, trasparente y ético, trasciende a todo tipo de organizaciones, debido a los numerosos escándalos financieros que atentan contra el crecimiento, desarrollo, progreso y bienestar de una sociedad. Las cooperativas son un tipo de empresas o asociatividad que, si bien es cierto, posee un fuerte desarrollo de la ética, democracia, solidaridad y responsabilidad social, deben sercapaces de hacer frentea empresas competidoras que, no siendo necesariamente cooperativas, poseen un considerable desarrollo moral. Lo que conduce a la consideración de la gestión tanto económica, social y medioambiental, en búsqueda de la competitividad y sustentabilidad de la compañía. Las cooperativas eléctricas en Chile son compañías autogestionadas, en su mayoría regionalistas, dedicadas a la subtransmisión de energía, las cuales poseen negocios interrelacionados. La presente investigación busca proporcionar una herramienta de autoaplicación que permite medir el desempeño de buen gobierno corporativo o, siendo más específico, de acuerdo a la esencia de una cooperativa, de un buen gobierno cooperativo, la cual fue sometida a una validación de contenido sistemática a través de la consulta a grupos de expertos, obteniendo como resultado un instrumento compuesto por 22 dimensiones que agrupan 73 reactivos, los cuales deben ser respondidos por más de un representante del gobierno corporativo de la cooperativa, con la finalidad de eliminar cualquier sesgo, producto de los conflictos de intereses. Para ello, se cuenta con una escala tipo Likert, dando luego el paso de la clasificación de los resultados. Por último, cabe señalar que para una futura investigación es importante someter el instrumento a un proceso de validación completa. 


\section{Gobierno corporativo}

El concepto de gobierno corporativo tiene su origen después de la segunda guerra mundial, producto de un crecimiento económico de diversos países en todo el mundo, especialmente Estados Unidos, ocasionando una proliferación de empresas que formaban verdaderos parques industriales. Es durante éste período en donde aparecen un sinnúmero de escándalos económicos y problemas de agencia, debido al abuso de poder e intereses deshonestos, ya que la mayoría de las compañías eran dirigidas por sus administradores y no por sus dueños (Veasey, 1993). Más tarde dicha situación tuvo su apogeo en países tales como Canadá, Australia, Japón, entre otros, en donde accionistas minoritarios deseaban conocer en profundidad el estado de la empresa en donde se encontraban sus inversiones (Sava, 2002), ya que el rumor de un inadecuado manejo financiero era latente. Dado lo anterior, fue necesario buscar algún mecanismo que fijase una serie de recomendaciones que ayudaran a mejorar el gobierno corporativo de las empresas, buscando integrar los intereses de todos los grupos de interés; es así que comienzan a aparecen los códigos de buen gobierno corporativo. El primer código fue elaborado en Reino Unido (Cadbury Report, 1992).

En este sentido, la OCDE (2004) ha desarrollado un conjunto de principios que buscan contribuir a la relación que tienen los grupos de interés que forman parte de la alta dirección, como: liberalización, no discriminación, trato racional y trato equivalente. Las finalidades de estos principios consisten en asistir a gobiernos de países miembros y no miembros en sus esfuerzos por evaluar y mejorar el marco legal, institucional y normativo sobre gobierno corporativo en sus países, así como proporcionar directrices y sugerencias para las bolsas de valores, los inversionistas, las sociedades y otras partes implicadas en el proceso de desarrollo de "buenas prácticas" de gobierno corporativo. Según Marín (2013), diversos países en todo el mundo han publicado un sinnúmero de guías en donde se agrupan prácticas de buen gobierno corporativo, tema que ha sido abordado por Freire y Repullo (2011), Kim y Purnanandam (2014), Toro y Ramírez (2012), Lai y Chen (2014), Ayuso, Rodríguez, García-Castro, y Arino (2014), Bueno y Santos (2012), Mason, y Simmons (2014), Duque, Carmona, y Rendón (2013), Rahim y Alam (2013), OCDE (2004) y Puentes, Velasco, y Villar (2009), sumando en total a lo menos 5 modelos que pretenden trasparentar las relaciones que se generan dentro de una empresa, en donde se busca la confianza, responsabilidad social, eficiencia económica y la integridad que son el modelo Asiático y de Oceanía, Europa del Sur y del Occidente, Países Nórdicos, Norteamericano y Latinoamericanos (GómezBetancourt y Zapata-Cuervo, 2013). Por otro lado, según Claessens y Yurtoglu (2013), existen dos categorías que pueden ser utilizadas como referente para conceptualizar gobierno corporativo: una de ellas se enfoca en los patrones de comportamiento y la otra basada en la estructura normativa de la corporación. 
Dando lo anterior, es importante precisar que el concepto de gobierno corporativo es polisémico, multidimensional y dinámico, ya que para Poyatos, Gámez, y Hernández (2009), Gutiérrez-García (2010) y Florez-Parra (2017) es un sistema que permiten gestionar y controlar las acciones en el interior de una compañía, la cual varía a través del tiempo, logrando consolidar una estructura que otorga derechos y responsabilidades a los diferentes stakeholders (Ayuso et al., 2014; Lai y Chen, 2014; Toro y Ramírez, 2012); en cambio para Bueno y Santos (2012) el gobierno corporativo se liga con la teoría de responsabilidad social empresarial, stakeholders y problemas de agencia, producto de las diversas responsabilidades que tiene la empresa con las partes interesadas y los eventuales conflictos que se pudiesen generar entre el propietario y el controlador de la compañía, lo cual es producto de la gestión encomendada al principal que pueden ocasionar diferencias (Duque et al., 2013; Mason y Simmons, 2014; Rahim y Alam, 2013).

Según la OCDE (2004) y Puentes et al. (2009) se comprende por gobierno corporativo un sistema que pretende evaluar y perfeccionar el marco legal de una compañía, en virtud de una serie de recomendaciones que buscan resguardar las interacciones entre el directorio y la empresa, basados en derechos y responsabilidades de cada stakeholders, en búsqueda de la eficiencia económica que es fruto de la confianza de sus miembros.

Por último, en Chile se han promulgado diversas disposiciones jurídicas que generan un marco regulador que atienden principalmente a las prácticas desarrolladas por las sociedades anónimas, siendo la más reciente la NCG 385 y la NCG 341 sobre estándares de gobierno corporativo que buscan "proveer información adecuada al público inversionista respecto de las políticas y prácticas de gobierno corporativo adoptadas por las sociedades anónimas abiertas", las que pudiesen ser aplicables a las cooperativas. Entre ellas, se encuentran:

- Ley 18.045 de Mercado de Valores. Regula el mercado de valores chileno.

- Ley 18.046 de Sociedades Anónimas. Norma los derechos fundamentales de los accionistas.

- Decreto Supremo de Hacienda N 702. Nuevo Reglamento de Sociedades Anónimas.

- Decreto Ley N³.538. Crea la Superintendencia de Valores y Seguros.

- Norma de Carácter General Número 341 de la SVS.

- Norma de Carácter General Número 385 de la SVS.

- Ley N¹9.832. Ley modifica la ley general de cooperativas. 
- Ley N¹9.496. Protección de los derechos de los consumidores.

- Decreto Ley N².757. Establece Normas sobre Asociaciones Gremiales.

- D.F.L. Núm. 5. Ley de Cooperativas.

- D.F.L. Núm. 101. Reglamento de la ley general de cooperativas.

Por otro lado, la teoría de agencia hace referencia a la consideración de los grupos de interés en las empresas, particularmente en la toma de decisiones, tema que ha sido abordado por Freeman (1984), Carroll (1991), Weiss (2006), Wheelen, Hunger, y Oliva (2007), Medina y Severino (2014, 2015), entre otros, los cuales concuerdan que los grupos de interés pueden ser personas naturales o jurídicas que poseen algún grado de interacción con la empresa, ya sea de manera directa o indirecta, pequeña o grande. La cantidad de stakeholders dependen del tipo de empresa y su relación con el medio. A continuación, se presenta el tipo de clasificación de acuerdo a la relación con la empresa (ver gráfica 1):

\section{Gráfica 1. Clasificación de Stakeholders.}

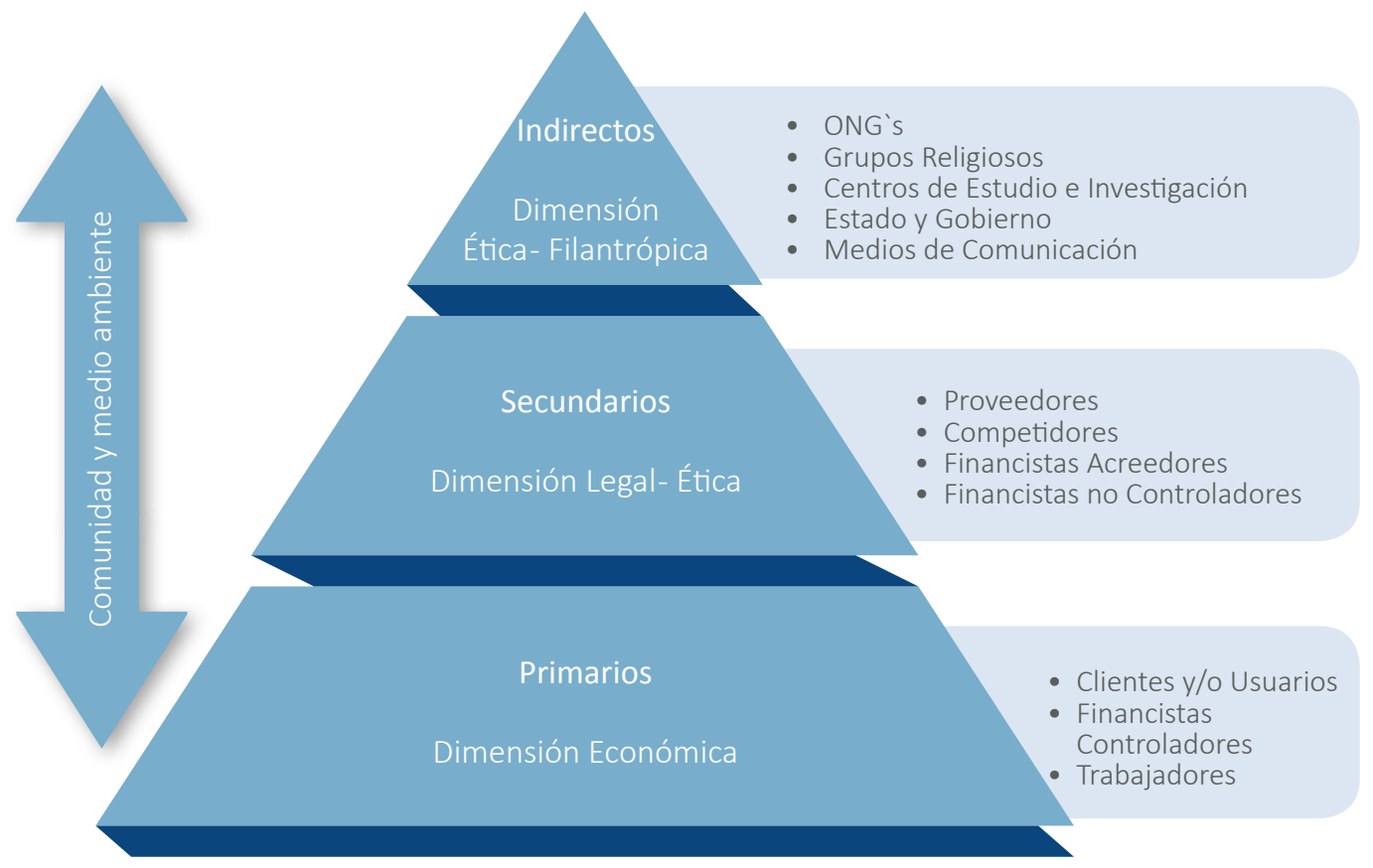

Fuente: Medina y Severino (2014).

Según Puentes et al. (2009) y Bueno y Santos (2012) es tradicional que el sistema de gobierno corporativo se encuentre íntimamente ligado con las teorías sobre problemas de agencia y estas, a su vez, con la teoría de los grupos 
de interés, producto de las diversas responsabilidades que tiene la empresa con las partes interesadas y las potenciales diferencias entre el propietario y el controlador de la compañía, lo cual es producto de la gestión encomendada al principal, que pueden ocasionar conflictos en la compañía (Duque et al., 2013; Mason y Simmons, 2014; Rahim y Alam, 2013; Severino-González y Medina, 2018). Dichos conflictos aparecen cuando la delegación de responsabilidades y funciones (ver gráfica 2) se encuentra trastocada por un comportamiento poco ético y egoísta, sumado a una baja regulación y mejor manejo de información por parte del agente, esto motivará la búsqueda de sus propios intereses por parte del mismo que en ocasiones se pueden superponer a los intereses del principal (Vergés, 2000).

\section{Gráfica 2. Delegación de funciones}

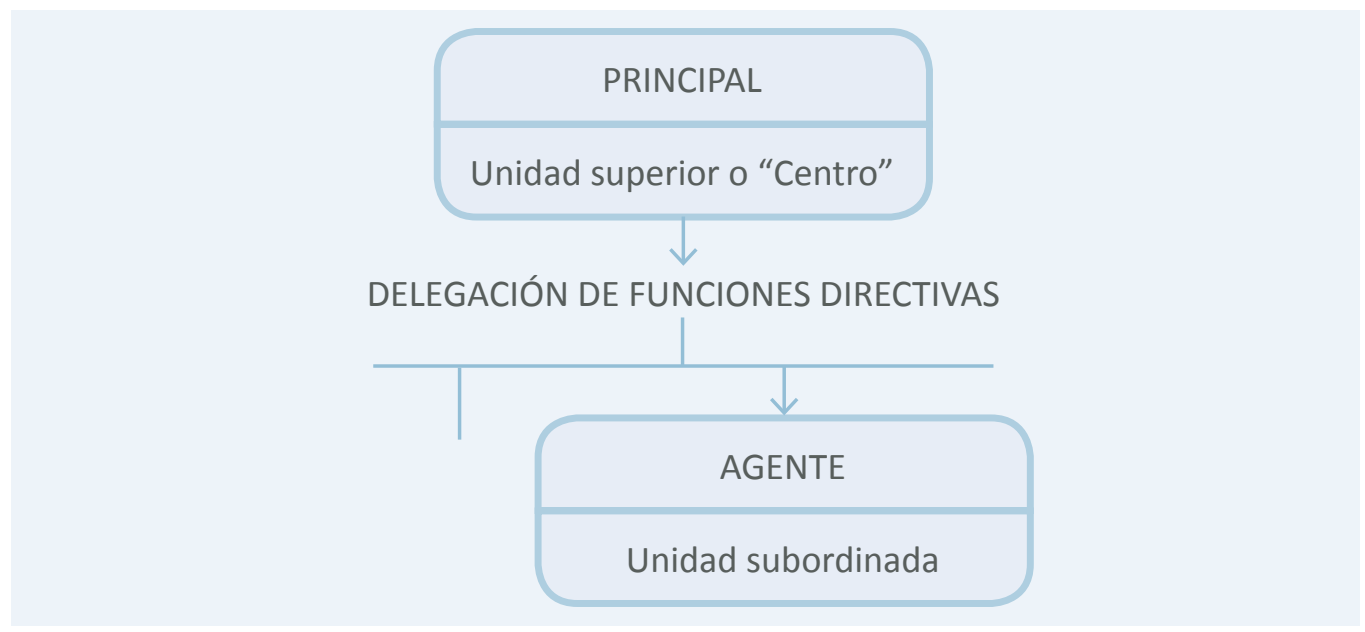

Fuente: Vergés (2000).

Como se ha mencionado, el concepto de gobierno corporativo se encuentra relacionado con la responsabilidad social empresarial, debido a que las empresas deben responder hasta el límite de su poder, lo que se encuentra condicionado por los efectos de sus acciones (Drucker, 1993), que responde a la emisión de juicio de valor (Freire y Repullo, 2011), fundamentados en la buen fe, lo que conduce al desarrollo de acciones basadas en principios y valores éticos que pretenden prevenir prácticas deshonestas y, por otro lado, desarrollar un alto nivel de integridad, despertando la confianza en los mercados (Kim y Purnanandam, 2014).

Para que una empresa sea considerada socialmente responsable, debe disponer de individuos socialmente responsables, los que, independientemente de quienes sean, en el lugar que se encuentren y la relación que pueden tener con alguna organización, son socialmente responsables consigo mismo y con 
los demás (Duque et al., 2013) para lo cual deben proceder bajo los valores de respeto, convivencia y tolerancia (Cortina, 2000), caracterizados por ser personas participativas y, sobre todo, hacer uso de sus derechos y cumplir con sus obligaciones.

Ahora bien, el compromiso que puedan asumir las organizaciones es de carácter trasversal en todas las entidades, independientemente de la personalidad jurídica que posea, finalidad que persiga o propósito que aspira, es decir, el aumento del bienestar de la sociedad local o global (Fernández, 2009). En el mismo sentido, el Foro de Expertos en RSE (2007) considera que el desarrollo de acciones socialmente responsables está condicionado por la definición de un proceso estratégico e integrador, que emana de directrices institucionales (CCE, 2001) y, para otros, se sitúa en el nivel corporativo (Moneva y Lizcano, 2004). Siendo reafirmado por Cabanelas (1997) y Wheelen et al. (2007), señalando que la responsabilidad social de las empresas fluye de la estrategia institucional. La responsabilidad empresarial precisa que sus acciones se centren en la concienciación de los impactos de sus actividades sobre la sociedad y el medioambiente (ISO, 2010), las cuales buscan otorgar una adecuada respuesta a las responsabilidades legales, éticas y discrecionales, lo que permite crea valor para los stakeholders (Aguilera y Puerto, 2012).

\section{Cooperativismo}

El bajo interés en desarrollar investigaciones que recojan la realidad de las cooperativas es debido al modelo que utilizan, basado en la solidaridad, democracia y empatía (Bustamante, 2009; Palomo y Sanchis, 2008; Moreno, 2014), situación que ha cambiado paulatinamente, alcanzando su máximo desarrollo después de la segunda guerra mundial (Arzadun, 2011; Medina, Mozas, Bernal, y Moral, 2014), ya que las empresas cooperativas poseen la particularidad que no tan sólo buscan asegurar la relación empleador/empleado, sino que además ofrecer bienes y servicios que sean capaces de satisfacer adecuadamente las necesidades de todos los stakeholders (López, Foncea, Álvarez, Servós, y Calderón, 2014), en búsqueda de un equilibrio social y ecológico (Ruiz y Quesada, 2014).

Las cooperativas son agrupaciones de personas que de manera voluntaria han decido trabajar de forma colectiva (Rivera, 2014; Vázquez, 2016a), siendo un modo válido de practicar economía (Vázquez, 2016b), manifestándose algunas diferencias con las sociedades anónimas convencionales o capitalistas (ver tabla 1), entre las más trascendentales, se pueden destacar la particularidad de su autonomía (García, Sánchez, Elizalde, y Fernández, 2017), la búsqueda de un fin social y económico, la democratización de la gestión y control (Pérez, Esteban, y Gargallo, 2009), la consideración de los valores cooperativistas y la participación 
exclusiva y de igualdad entre los cooperados (Sempere y García, 2014). Dicha proliferación de empresas cooperativas ha conducido a investigadores a generar clasificaciones que facilitan el estudio, según Vargas (2015), Martínez, Torres, Jordán, Guevara, y Hernández (2015), Borda, Otárola, y Escobar (2016) en cooperativas de consumo, producción, crédito, ahorro, trabajo, bienes, servicios, agrícolas, entre otras.

Tabla 1. Comparación entre empresas cooperativas y capitalistas.

\begin{tabular}{|c|c|c|}
\hline Características & Empresas Cooperativas & Empresas Capitalistas \\
\hline Titulares & Socios cooperativistas & Accionistas \\
\hline Objetivos & $\begin{array}{l}\text { Proporcionar bienes o } \\
\text { servicios a sus asociados } \\
\text { o a terceros procurando } \\
\text { un beneficio directo a los } \\
\text { cooperativistas. }\end{array}$ & $\begin{array}{l}\text { Maximizar los } \\
\text { rendimientos con base en } \\
\text { el capital aportado. }\end{array}$ \\
\hline Control y dirección & $\begin{array}{l}\text { Democracia, generalmente a } \\
\text { cargo de los socios. }\end{array}$ & $\begin{array}{l}\text { En función del capital } \\
\text { invertido. La dirección se } \\
\text { delga a funcionarios que } \\
\text { son contratados por la } \\
\text { empresa. }\end{array}$ \\
\hline Poder de decisión & $\begin{array}{l}\text { A cargo de la asamblea } \\
\text { general, con base en el } \\
\text { principio de igualdad. Un } \\
\text { hombre - un voto. }\end{array}$ & $\begin{array}{l}\text { A cargo de los accionistas } \\
\text { de acuerdo con el capital } \\
\text { aportado. }\end{array}$ \\
\hline Capital & $\begin{array}{l}\text { Variable (aportaciones } \\
\text { sociales). }\end{array}$ & Fijo o variable. \\
\hline $\begin{array}{l}\text { Condiciones de } \\
\text { ingreso }\end{array}$ & $\begin{array}{l}\text { Libre, sujeta a la aprobación } \\
\text { de los cooperativistas. }\end{array}$ & $\begin{array}{l}\text { Restringida a la } \\
\text { adquisición de acciones. }\end{array}$ \\
\hline $\begin{array}{l}\text { Ganancias o } \\
\text { excedentes }\end{array}$ & $\begin{array}{l}\text { Se capitalizan o distribuyen } \\
\text { equitativamente, con base en } \\
\text { el trabajo aportado. }\end{array}$ & $\begin{array}{l}\text { Se distribuyen en función } \\
\text { de la tenencia accionaria. }\end{array}$ \\
\hline $\begin{array}{l}\text { Estructura de } \\
\text { apoyo }\end{array}$ & $\begin{array}{l}\text { Federación, uniones y } \\
\text { Confederaciones. }\end{array}$ & $\begin{array}{l}\text { Confederaciones } \\
\text { patronales. }\end{array}$ \\
\hline $\begin{array}{l}\text { Organismos } \\
\text { internacionales más } \\
\text { representativos. }\end{array}$ & $\begin{array}{l}\text { Alianza cooperativa } \\
\text { Internacional y World Council } \\
\text { of Credit Unions, Inc. }\end{array}$ & No determinada. \\
\hline
\end{tabular}

Fuente: Lara (2009). 
Las sociedades cooperativistas se encuentran fuertemente ligadas con la economía social (López et al., 2014; Román, 2014) las que, igual que las empresas convencionales, deben poseer recursos y capacidades que sean conductores de ventajas competitivas y que les permitan hacer frente a los mercados en donde compiten (Cassio y Taddei, 2017), aportando al desarrollo y progreso de una sociedad (Colón, 2014; Cotte y Zambrano, 2014), potenciado por la materialización de valores que dirigen el proceder de las mismas $(\mathrm{ACl}, 1997)$, debido a la profunda relación con la consideración de estrategias de responsabilidad social organizacional (Muñoz y Tirado, 2014; Pérez, 2016).

\section{Metodología de la Investigación}

El desarrollo de esta investigación se ha efectuado bajo el alero de la metodología cualitativa (Bunge, 2004; Hernández, Fernández, y Baptista, 2010), la que consta de la construcción teórica sobre cooperativismo, gobierno corporativo, responsabilidad social, grupos de interés, con un fuerte apoyo con las normas NCG 341 y N³85 de la SVS; lo cual permite obtener una revisión sistemática del estado actual sobre la materia, dando paso a la declaración de una batería de afirmaciones que son reactivos y que dan respuesta al objetivo principal de ésta investigación.

Es importante precisar que la presente investigación ha permitido diseñar una propuesta de buen gobierno para cooperativas eléctricas en Chile. El mencionado fue sometido a un proceso de validación que se desarrolló a través de la consulta de personas ligadas a las cooperativas, al mundo académico, autoridades, entre otras, para lo cual se utilizó el método delphi (Hernández et al., 2010), divido en tres etapas: preparatoria, consulta y consenso (García y Suárez, 2013), para lo que se empleó la técnica de entrevista abierta no estructurada (Canales, 2006), antes y durante el desarrollo de la investigación. Dichos grupos de expertos están compuestos por directivos superiores de cooperativas, socios de cooperativas, expertos en cooperativismo, entre otros expertos (ver tabla 2), en donde se interrogaba sobre la consistencia, coherencia, pertinencia, claridad, entre otros aspectos del instrumento (Soriano, 2014), ocasionando mejoras en la redacción, eliminación de reactivos y la incorporación de otros que no estaban considerados. Este proceso se repitió tres veces, permitiendo disponer del producto final de esta investigación. 
Tabla 2: Grupos de expertos.

\begin{tabular}{|c|c|}
\hline Grupos de expertos & Número \\
\hline Profesionales & 15 \\
\hline Académicos & 4 \\
\hline Autoridades & 2 \\
\hline Total & 21 \\
\hline
\end{tabular}

Fuente: Elaboración propia.

Lo que ha permitido obtener una propuesta compuesta por 73 reactivos expresados en afirmaciones agrupados en 22 dimensiones (ver anexo 1), siendo de autoaplicación, en donde se debe responder a través de una escala tipo likert de manera anónima, franca, sincera, considerando la situación actual de la empresa en relación a la afirmación que se propone, es de solo cuatro alternativas de respuestas (ver tabla 3).

Tabla 3. Definición de las opciones de respuesta.

\begin{tabular}{|c|c|c|}
\hline Opciones & Definición & Valoración \\
\hline $\begin{array}{l}\text { Nunca } \\
\text { (NU) }\end{array}$ & $\begin{array}{l}\text { La organización nunca destina parte de sus } \\
\text { esfuerzos para desarrollar prácticas de buen } \\
\text { gobierno cooperativo. }\end{array}$ & 0 \\
\hline $\begin{array}{l}\text { A veces } \\
(\mathrm{AV})\end{array}$ & $\begin{array}{l}\text { La organización no es constante en el desarrollo } \\
\text { de prácticas de buen gobierno cooperativo. }\end{array}$ & 1 \\
\hline $\begin{array}{l}\text { Generalmente } \\
\text { (GN) }\end{array}$ & $\begin{array}{l}\text { La organización destina la mayor parte de } \\
\text { su tiempo en desarrollar prácticas de buen } \\
\text { gobierno cooperativo. }\end{array}$ & 2 \\
\hline $\begin{array}{l}\text { Siempre } \\
\text { (SI) }\end{array}$ & $\begin{array}{l}\text { La organización dedica todos sus esfuerzos } \\
\text { para desarrollar prácticas sistemáticas de buen } \\
\text { gobierno cooperativo. }\end{array}$ & 3 \\
\hline
\end{tabular}

Fuente: Elaboración propia. 
Cabe señalar que, para una adecuada respuesta de este instrumento, se debe comprender por gobierno corporativo un sistema que permite gestionar las acciones de la cooperativa bajo los valores de la solidaridad, confianza, trasparencia y buena fe, que facilitan alcanzar el objetivo social y económico de la organización, otorgando adecuadas respuestas a las necesidades y requerimientos de todos los grupos de interés.

Por otro lado, en cuanto al análisis de los resultados una vez aplicado el instrumento, se debe tener claridad del puntaje obtenido que es producto de la valoración, el cual debe ser estimado a través de la suma de cada una de los reactivos de manera global, el que debe ser clasificado en los siguientes criterios (ver tabla 4).

Tabla 4. Criterios de clasificación de valoración

\begin{tabular}{|c|c|}
\hline Criterio & Puntuación \\
\hline B & Menos de 73 \\
\hline A & Entre 74 y 176 \\
\hline A+ & Entre 147 y 219 \\
\hline
\end{tabular}

Fuente: Elaboración propia

Por último, una vez clasificado el puntaje obtenido en los criterios de valoración, se debe tener claridad del nivel de desempeño que posee la cooperativa en relación al desarrollo de un buen gobierno corporativo, para lo cual se presenta la tabla 5, en donde se entrega una explicación del comportamiento de la empresa. 
Tabla 5. Clasificación del nivel de desempeño

\begin{tabular}{|c|c|c|}
\hline Criterio & $\begin{array}{c}\text { Nivel de } \\
\text { desempeño }\end{array}$ & \multicolumn{1}{c|}{\begin{tabular}{c} 
Explicación \\
\hline B
\end{tabular}} \\
\hline A & Malo & $\begin{array}{l}\text { La cooperativa nunca o a veces realiza } \\
\text { acciones a favor de sus grupos de interés, } \\
\text { no considerando las dimensiones de buen } \\
\text { gobierno corporativo. }\end{array}$ \\
\hline A & Regular & $\begin{array}{l}\text { La cooperativa realiza acciones a favor de sus } \\
\text { grupos de interés, pero no cumple con cada } \\
\text { una de las dimensiones de buen gobierno } \\
\text { corporativo. }\end{array}$ \\
\hline Excelente & $\begin{array}{l}\text { La cooperativa es capaz de satisfacer } \\
\text { adecuadamente los requerimientos de } \\
\text { los grupos de interés en relación a las } \\
\text { dimensiones de buen gobierno corporativo. }\end{array}$ \\
\hline
\end{tabular}

Fuente: Elaboración propia

\section{Reflexiones finales}

El mencionado instrumento de buen gobierno corporativo para cooperativas eléctricas en Chile (ver anexo 1) es un esfuerzo desarrollado por un equipo de expertos que, de manera directa e indirecta, han colaborado para la creación del mismo, el cual permite identificar aquellas prácticas que las cooperativas podrían desarrollan de manera armónica y equilibrada con sus diversos grupos de interés y en particular con sus cooperados. El instrumento está compuesto por 22 dimensiones, sumando en total 73 reactivos. Las dimensiones que poseen una mayor cantidad de prácticas son: Gestión de riesgo, Inducción e Información, las cuales consideran acciones que atienden a la diversidad de un modelo de negocios con las particularidades de una cooperativa.

Por otro lado, las cooperativas presentan un fuerte desarrollo después de la segunda guerra mundial, lo cual coincide con los primeros estudios ligados con gobierno corporativo, debido a los numerosos sucesos que afectaron la economía de los países que se encontraban en plena proliferación del tejido empresarial, manifestados en grandes empresas manufactureras que buscaban únicamente la rentabilidad por sobre el bienestar de sus trabajadores y, en el caso de las cooperativas, los cooperados que de manera voluntaria decidieron trabajar en conjunto. 
Las cooperativas, al igual que las empresas convencionales, deben considerar en su planificación la consideración de prácticas ligadas con el buen gobierno corporativo, ya que debe ser una declaración que emane de la alta administración, comprometiendo a cada uno de los socios o cooperados y a todos los trabajadores, ya que la empresa es el fiel retrato de los individuos que la componen, dando paso a la gestión social y económica, lo cual permite la creación de valor para todos los grupos de interés, producto de una adecuada respuesta a sus necesidades.

Ahora bien, en Chile el modelo cooperativo está siendo invisible para una gran parte de los ciudadanos, inclusive por las autoridades, por diferentes factores, entre ellos: la disposición de un marco legal que presenta ciertos grados de solidez para compañías que adoptan una personalidad jurídica distinta a las cooperativas, existiendo sólo normativas genéricas, difusas y poco claras.

Actualmente las cooperativas que sobreviven a las presiones del mercado han tenido un factor determinante en su gestión, que se genera en la falta de la existencia de un buen gobierno corporativo los factores del fracaso están determinados por las propias condiciones internas, por la falta de identidad, un carente liderazgo y un disminuido profesionalismo, provocando un escuálido sistema de gobierno cooperativo.

Es importante y de suma urgencia que las cooperativas posean directrices claras sobre gobierno corporativo, materializada en una sólida estrategia institucional, permitiendo, en cierta medida, desplegar planes y programas que se materialicen en acciones, que contribuyan a mejorar el grado de satisfacción de los grupos de interés, lo cual se fundamenta en la reacción frente a los estímulos de la alta administración, que incide en la configuración de la cultura organizacional y, por ende, en el nivel de percepción de los cooperados. 


\section{Referencias bibliográficas}

ACl (1997). Declaración de la Alianza Cooperativa Internacional. 850 día internacional de las cooperativas de la ACl, Geneva, 7 de julio de 2007.

Aguilera, A., y Puerto, D. (2012). Crecimiento empresarial basado en responsabilidad social. Revista Pensamiento \& Gestión, 32, 01-26.

Arzadun, P. (2011). Globalización económica y cooperativismo. Estudio empírico sobre el sector cooperativo argentino. Revista de Economía Pública, Social y Cooperativa, 72, 215- 235.

Ayuso, S., Rodríguez, M., García-Castro, R., y Arino, M. (2014). Maximizing stakeholders' interests: an empirical analysis of the stakeholder approach to corporate governance. Business \& Society, 53(32), 414-439.

Borda., J., Otárola, J., y Escobar, A. (2016). Proceso de toma de decisiones en las cooperativas de ahorro y crédito de Barranquilla. Revista Visión Contable, 14(14), 105-125.

Bueno, J., y Santos, D. (2012). Teoría de la agencia en la determinación de la estructura de capital. Casos sectores económicos del Departamento del Valle del Cauca. Revista Prolegómenos - Derechos y Valores, 15(30), 161-176.

Bunge, M. (2004). La metodología científica (3ra Ed.). México: Siglo XXI.

Bustamante, A. (2009). Cooperativismo de trabajo asociado y estrategia: revisión de literatura. Pensamiento \& Gestión, 27, 201-234.

Cabanelas, J. (1997). Dirección de empresas: bases en un entorno abierto y dinámico. Madrid: Editorial Pirámide.

Cadbury Report. (1992). Report of the committee on the financial aspects of corporate governance. Londres: European Corporate Governance Institute.

Canales, M. (2006). Metodologías de investigación social. Introducción a los oficios. Santiago de Chile: LOM.

Carroll, A. (1991). The pyramid of corporate social responsability: towards the moral management of organisational stakeholders. Business Horizons, 34(4), 39-38.

Cassio, E., y Taddei, I. (2017). Gobernanza y competitividad en cooperativas pesqueras de ribera del sistema lagunar Topolobampo-Ohuira-Santa María en Sinaloa, México. Revista Idelcoop, 221, 49-75. 
CCE. (2001). Libro verde: fomentar un marco europeo para responsabilidad social de las empresas. Bruselas: Comisión de las Comunidades Europeas.

Claessens, S., y Yurtoglu, B. (2013). Corporate governance in emerging markets: a survey. Social Sciencie Research Network, 15, 1-33.

Colón, R. (2014). El Principio de autonomía cooperativa frente al Estado: su articulación bajo la legislación de Puerto Rico. Boletín de la Asociación Internacional de Derecho Cooperativo, 48, 177-190.

Cortina, A. (2000). La ética de la sociedad civil (4ta Ed.).Madrid: Editorial Anaya.

Cotte, A., y Zambrano, Y. (2014). Cooperativismo y desarrollo local: un análisis de sistematización de experiencias en las cooperativas de lecheros. Spanish Journal of Rural Development, 5(1), 1-19.

D.F.L. Núm. 101, Aprueba reglamento de la ley general de cooperativas. Ministerio de Economía, Fomento y Reconstrucción; Subsecretaría de Economía, Fomento y Reconstrucción, Santiago, Chile, 25 de enero de 2007.

D.F.L. Núm. 5, Ley de Cooperativas. Fija texto refundido, concordado y sistematizado de la ley general de cooperativas. Ministerio de Economía, Fomento y Reconstrucción; Subsecretaría de Economía, Fomento y Reconstrucción, Santiago, Chile, 17 de febrero de 2004.

Decreto Ley 3.538. Crea la Superintendencia de Valores y Seguros. Diario Oficial de la República de Chile, Santiago, Chile, 9 de diciembre de 1980.

Decreto Ley N².757 Establece Normas sobre Asociaciones Gremiales. Ministerio de Hacienda. Diario Oficial de la República de Chile, Santiago, Chile, 04 de julio de 1979.

Decreto Supremo 702. Aprueba nuevo reglamento de sociedades anónimas. Ministerio de Hacienda. Diario Oficial de la República de Chile, Santiago, Chile, 27 de mayo 2011.

Drucker, P. (1993). Managing for the future. New York: Routledge.

Duque, Y., Cardona, M., y Rendón, J. (2013). Responsabilidad social empresarial: teorías, índices, estándares y certificaciones. Revista Cuadernos de Administración Universidad del Valle, 29(50), 196-206.

Fernández, R. (2009). Responsabilidad social corporativa. España: Editorial Club Universitario. 
Florez-Parra, J. (2017). El gobierno corporativo en el ámbito del sector público: un estudio bibliométrico en las revistas ubicadas en el área de administración pública. Revista Facultad de Ciencias Económicas: Investigación y Reflexión, 25(1), 161-175.

Foro de Expertos sobre RSE (2007). Informe del foro de expertos en responsabilidad social de las empresas. España.

Freeman, C. (1984). Strategic management: a stakeholders approach. Boston: Pitman.

Freire, J., y Repullo, J. (2011). Good governance of publicly-produced health services: ideas for moving forward. Ciência \& Saúde Coletiva, 16(6), 27332742.

García, M., y Suárez, M. (2013). El método Delphi para la consulta a expertos en la investigación científica. Revista Cubana de Salud Pública, 39(2), 253-267.

García, G., Sánchez, V., Elizalde, D., y Fernández A. (2017). La gestión social de cooperativas de ahorro y crédito en Ecuador. Cooperativismo y Desarrollo, 5(1), 47-59.

Gómez-Betancourt, G., y Zapata-Cuervo, N. (2013). Gobierno corporativo: una comparación de códigos de gobierno en el mundo, un modelo para empresas latinoamericanas familiares y no familiares. Revista Entramado, 9(2), 98-117.

Gutiérrez-García, E. (2010). Gobierno corporativo y comunicación empresarial ¿qué papel cumplen los directores de comunicación en España? Palabra Clave, 13(1), 147-160.

Hernández, R., Fernández, C., y Baptista, C. (2010). Metodología de la investigación (5ta. Ed) México: McGraw-Hill.

International Organizational for Standardization. (2010). ISO 26000 Social Responsibiliy. Recuperado de www.iso.org/iso/social_responsibility.

Kim, E., y Purnanandam, A. (2014). Seasoned equity offerings, corporate governance, and investments. Review of Finance, 18(3), 1023-1057.

Lai, J., y Chen, L. (2014). The valuation effect of corporate governance on stakeholders wealth: evidence from strategic alliance. International Review of Economic \& Finance, 32, 117-131.

Lara, G. (2009). Cooperativas: entre economía social, economía solidaria y tercer sector. En G. Lara Gómez, y A. Urbiola Solís (Coords.). Visión global 
de las cooperativas (pp. 17-71). México: Plaza y Valdés editores-Universidad Autónoma de Querétaro.

Ley 18.045. Ley de Mercado de Valores. Diario Oficial de la República de Chile, Santiago, Chile, 22 de octubre de 1981.

Ley 18.046. Ley sobre Sociedades Anónimas. Diario Oficial de la República de Chile, Santiago, Chile, 22 de octubre de 1981.

Ley $N^{\circ}$ 19.496. Normas sobre protección de los derechos de los consumidores. Diario Oficial de la República de Chile, Santiago, Chile, de 7 de marzo de 1997.

Ley $N^{\circ}$ 19.832. Ley modifica la ley general de cooperativas. Diario Oficial de la República de Chile, Santiago, Chile, 04 de noviembre de 2002.

López, J., Foncea, M., Álvarez, M., Servós, C., y Calderón, P. (2014). Evolución del comportamiento estratégico de las cooperativas versus empresas capitalistas: una aproximación descriptiva al efecto crisis. Revista de Estudios Cooperativos, 116, 77-102.

Marín, E. (2013). A propósito de un buen gobierno cooperativo. Medellín: Banco Cooperativo Coopcentral.

Martínez, J., Torres, V., Jordán, H., Guevara, G., y Hernández, N. (2015). Clasificación de fincas lecheras pertenecientes a cooperativas de créditos y servicios. Revista De Producción Animal, 27(1), 17-24.

Mason, C., y Simmons, J. (2014). Embedding corporate social responsibility in corporate governance: a stakeholder systems approach. Journal of Business Ethics, 119(1), 77-86.

Medina, A., y Severino, P. (2014). Responsabilidad empresarial: generación de capital social de las empresas. Revista Contabilidad y Negocios, 17(9), 63-72.

Medina, A., y Severino, P. (2015). Capital social: creación de valor económico para el accionista. En G. Rodríguez (Ed.), El hombre y su medio ambiente social; introducción, concepto y percepciones. Guanajuato: Universidad de Guanajuato.

Medina, M., Mozas, A., Bernal, E., y Moral, E. (2014). Factores determinantes para la exportación en las empresas cooperativas oleícolas andaluzas. Revista de Economía Pública, Social y Cooperativa, 81, 241-262.

Moneva, J., y Lizcano, J. (2004). Marco conceptual de la responsabilidad social corporativa. Trabajo presentado en Asociación Española de Contabilidad y Administración de Empresas (AECA). Madrid, diciembre de 2004. 
Moreno, J. (2014). Los valores según la Alianza Cooperativa Internacional (ACI). Revista Jurídica de Economía Social y Cooperativa, 25, 371-393.

Muñoz, R., y Tirado, P. (2014). Responsabilidad social y transparencia a través de la Web: un análisis aplicado a las cooperativas agroalimentarias españolas. Revista de Estudios Cooperativos, 114, 84-105.

Norma de carácter general $\mathrm{N}^{\circ} 341$. Superintendencia de Valores y Seguros, Santiago, Chile, 29 de noviembre de 2012.

Norma de carácter general $N^{\circ} 385$. Superintendencia de Valores y Seguros, Santiago, Chile, 08 de julio de 2015.

OCDE. (2004). OCDE principles of corporate governance. Paris: Organisation for Economic Co-operation and Development.

Palomo, R., y Sanchis J. (2008). Un análisis del crédito cooperativo en España: situación actual, expansión territorial y proyección estratégica. Estudios de Economía Aplicada, 26(1), 89-132

Pérez, F. J., Esteban, L., y Gargallo, A. (2009). Participación, gobierno democrático y resultados cooperativos: una perspectiva de RSE. Revista de Economía Pública, Social y Cooperativa, 65, 163-190.

Pérez, P. (2016). Gobierno y gobernabilidad en las empresas mutuales. Identificación. Concepto. Aplicación. Económicas CUC, 37(2), 177-194.

Poyatos, R., Gámez, M., y Hernández, J. (2009). El buen gobierno corporativo en las sociedades cooperativas. Revista de Estudios Cooperativos, 98, 118-140.

Puentes, R., Velasco, M., y Vilar, J. (2009). El bueno gobierno corporativo en las sociedades cooperativas. Revista de Estudios Cooperativos, 98, 118-140.

Rahim, M., y Alam, S. (2013). Convergence of corporate social responsibility and corporate governance in weak economies: the case of Bangladesh. Journal of Business Ethics, 121(4), 607-620.

Rivera, C. (2014). El cooperativismo una vía para el desarrollo económico y social en el modelo cubano. Revista Cooperativismo y Desarrollo, 2(1), 1-25.

Román, C. (2014). Las cooperativas españolas y los ciclos económicos. Un análisis comparado. CIRIEC-España, 80, 77-109.

Ruiz, I., y Quesada, J. (2014). Los principios cooperativos como capital intangible ante los desafíos del cooperativismo. Intangible Capital, 10(5), 897-921. 
Sava, T. (2002). Gobierno corporativo en los Estados Unidos a comienzos del siglo XXI y su posición en ámbito global. Revista Chilena de Derecho, 29(3), 661671.

Sempere, J., y García, E. (2014). ¿Qué papel pueden tener las cooperativas en una transición postcarbono? Reflexiones desde el cooperativismo en Cataluña. Revista de Economía Crítica, 18, 31-47.

Severino-González, P., y Medina, A. (2018). Modelo de gestión integrado: responsabilidad empresarial y buen gobierno corporativo. En E. Wulf (Ed.), Responsabilidad social empresarial: un desafío corporativo. La Serena: Editorial Universidad de La Serena.

Soriano, A. (2014). Diseño y validación de instrumentos de medición. Diá-logos, 13(14), 19-40.

Toro, C., y Ramírez, H. (2012). El gobierno corporativo en la cooperativa de trabajo asociado Recuperar CTA. Revista Entramado, 8(2), 94-104.

Vargas, C. (2015). Las cooperativas de crédito y su posición dentro del modelo cooperativo. Integración frente a diferenciación en el marco de la reforma del sistema financiero. Revista de Estudios Cooperativos, 117, 50-76.

Vázquez, M. (2016a). Acción colectiva y desarrollo rural: las instituciones de organización de la calidad. Cooperativismo \& Desarrollo, 23(107), 5-19.

Vázquez, M. (2016b). Las sociedades cooperativas, una expresión de economía social solidaria. El caso de la cooperativa de productores de artesanías Erandi. Economía y Sociedad, 20(34), 17-37.

Veasey, E. N. (1993). The emergence of corporate governance as a new legal discipline. Business Lawyer, 48(4), 1267-1270.

Vergés, J. (2000). Privatizations in Spain: process, policies and goals. European Journal of Law and Economics, 9(23), 255-280.

Weiss, J. (2006). Ética en los negocios: Un enfoque de administración de los stakeholders y de casos (4ta Ed.). México: Thompson.

Wheelen, T., Hunger, J., y Oliva, I. (2007). Administración estratégica y políticas de negocio. Conceptos y casos. México: Pearson. 


\section{Anexo 1}

\begin{tabular}{|c|c|c|c|c|c|c|}
\hline Dimensión & $\mathrm{N}^{\circ}$ & Descripción & NU & AV & GE & $\mathrm{SI}$ \\
\hline Administración & 1 & $\begin{array}{l}\text { La cooperativa dispone de política clara sobre } \\
\text { limitación de funciones entre los integrantes del } \\
\text { consejo de administración y gerente general. }\end{array}$ & & & & \\
\hline Asesorías & 2 & $\begin{array}{l}\text { El consejo considera la asesoría de un experto } \\
\text { ajeno a la cooperativa para la detección e } \\
\text { implementación de eventuales mejoras en } \\
\text { diversas instancias. }\end{array}$ & & & & \\
\hline \multirow[t]{3}{*}{ Auditor externo } & 3 & $\begin{array}{l}\text { El consejo se reúne al menos una vez cada } \\
\text { semestre para revisar el programa y evaluar el } \\
\text { avance del plan anual de auditoría. }\end{array}$ & & & & \\
\hline & 4 & $\begin{array}{l}\text { El consejo revisa eventuales diferencias } \\
\text { detectadas en la auditoría respecto de prácticas } \\
\text { contables, sistemas administrativos y auditoría } \\
\text { interna a través de la carta de control. }\end{array}$ & & & & \\
\hline & 5 & $\begin{array}{l}\text { El consejo analiza las deficiencias graves que se } \\
\text { hubieran detectado, avisando a las autoridades } \\
\text { competentes, como a su vez genera planes de } \\
\text { mejoras. }\end{array}$ & & & & \\
\hline \multirow[t]{3}{*}{ Auditoría interna } & 6 & $\begin{array}{l}\text { El consejo se reúne frecuentemente con el } \\
\text { auditor interno para la revisión del programa } \\
\text { anual de auditoría. }\end{array}$ & & & & \\
\hline & 7 & $\begin{array}{l}\text { El consejo frente a eventuales deficiencias } \\
\text { graves que se hubieran detectado comunica } \\
\text { a organismos fiscalizadores, como la junta de } \\
\text { vigilancia y departamento de cooperativas. }\end{array}$ & & & & \\
\hline & 8 & $\begin{array}{l}\text { El consejo ha implementado un proceso } \\
\text { sistemático de gestión y control de riesgos, que } \\
\text { se encuentre en operación, el cual considere la } \\
\text { verificación de la efectividad de las directrices } \\
\text { estratégicas. }\end{array}$ & & & & \\
\hline Capacitación & 9 & $\begin{array}{l}\text { El consejo dispone de procedimientos claros de } \\
\text { capacitación para los miembros del consejo de } \\
\text { administración. }\end{array}$ & & & & \\
\hline
\end{tabular}




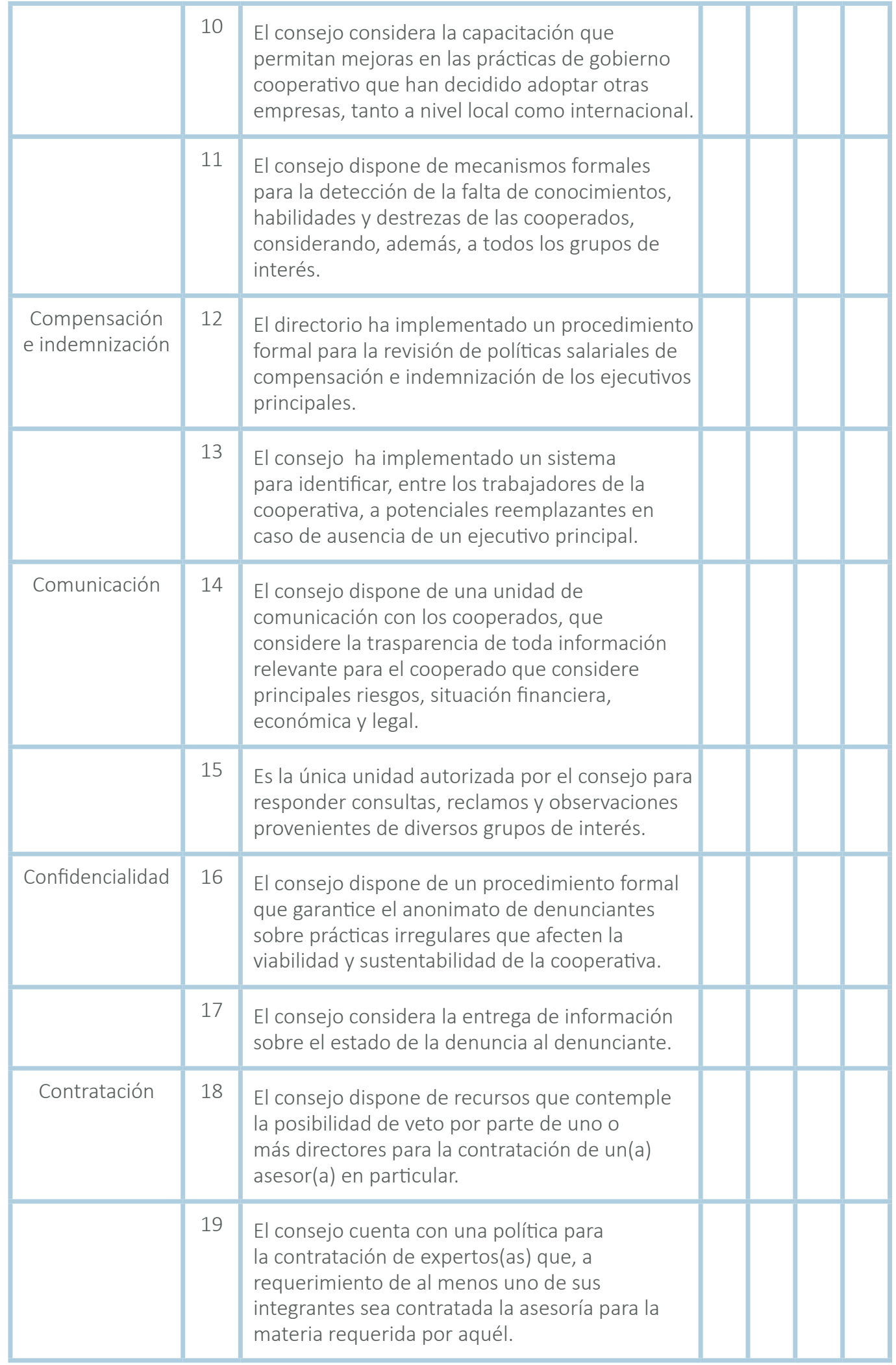




\begin{tabular}{|c|c|c|}
\hline \multirow[t]{2}{*}{ Directorio } & 20 & $\begin{array}{l}\text { El consejo ha establecido procedimiento para } \\
\text { detectar y reducir barreras organizacionales, } \\
\text { sociales o culturales que pudieren estar } \\
\text { inhibiendo la natural diversidad de las } \\
\text { capacidades, visiones, características y } \\
\text { condiciones que se habría dado en el consejo } \\
\text { de no existir esas barreras. }\end{array}$ \\
\hline & 21 & $\begin{array}{l}\text { El consejo mantiene un procedimiento de } \\
\text { mejoramiento continuo que, sin perjuicio de las } \\
\text { obligaciones legales, contemple expresamente } \\
\text { la determinación del número mínimo de } \\
\text { reuniones ordinarias. El tiempo promedio } \\
\text { mínimo de dedicación presencial y remota a las } \\
\text { mismas y la antelación con la que se debiera } \\
\text { remitir la citación y los antecedentes necesarios } \\
\text { para la adecuada realización de aquéllas. } \\
\text { Reconociendo las características particulares } \\
\text { de la entidad así como también la diversidad } \\
\text { de experiencias, condiciones y conocimientos } \\
\text { existentes en el directorio, según la complejidad } \\
\text { de las materias a tratar. }\end{array}$ \\
\hline & 22 & $\begin{array}{l}\text { El consejo ha implementado un procedimiento } \\
\text { formal que pueda informar a los socios } \\
\text { oportunamente con al menos tres meses de } \\
\text { antelación a la junta de accionistas en que se } \\
\text { elegirán directores, acerca de la diversidad } \\
\text { de capacidades, condiciones, experiencias y } \\
\text { visiones que en opinión del directorio resulta } \\
\text { aconsejable formen parte del mismo para que } \\
\text { este se encuentre con las mejores condiciones } \\
\text { de velar por el interés social. }\end{array}$ \\
\hline & 23 & $\begin{array}{l}\text { El consejo en el procedimiento de elecciones o } \\
\text { en los estatutos ha considerado un mecanismo } \\
\text { formal para informar a los cooperados antes de } \\
\text { la votación correspondiente, considerando la } \\
\text { experiencia, profesión u oficio del candidato a } \\
\text { director u otras competencias. }\end{array}$ \\
\hline Ética & 24 & $\begin{array}{l}\text { El consejo de administración cuenta con un } \\
\text { procedimiento o mecanismo de capacitación } \\
\text { permanente para la actualización de } \\
\text { conocimientos, relacionados con los derechos y } \\
\text { deberes de los directivos. }\end{array}$ \\
\hline
\end{tabular}




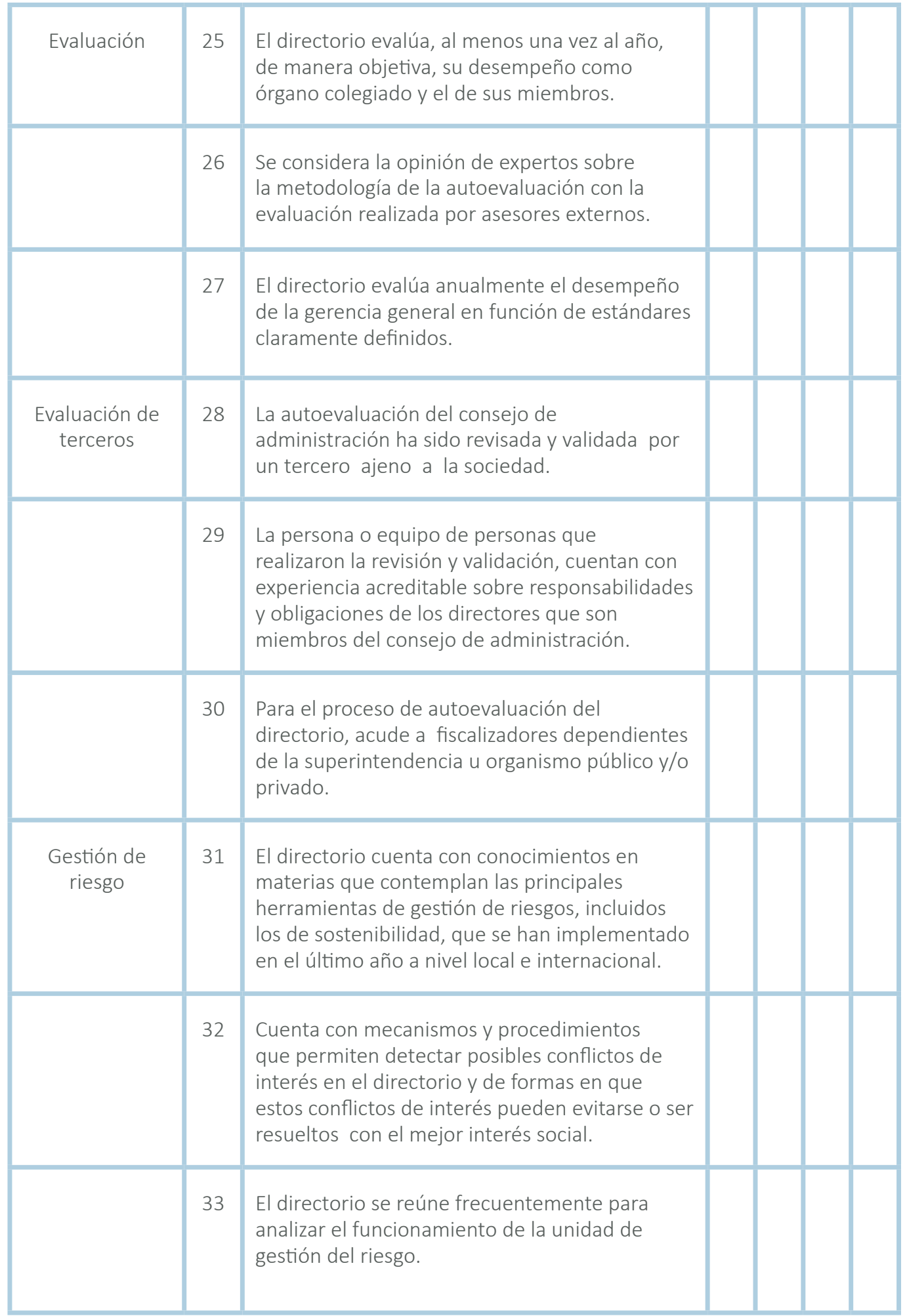




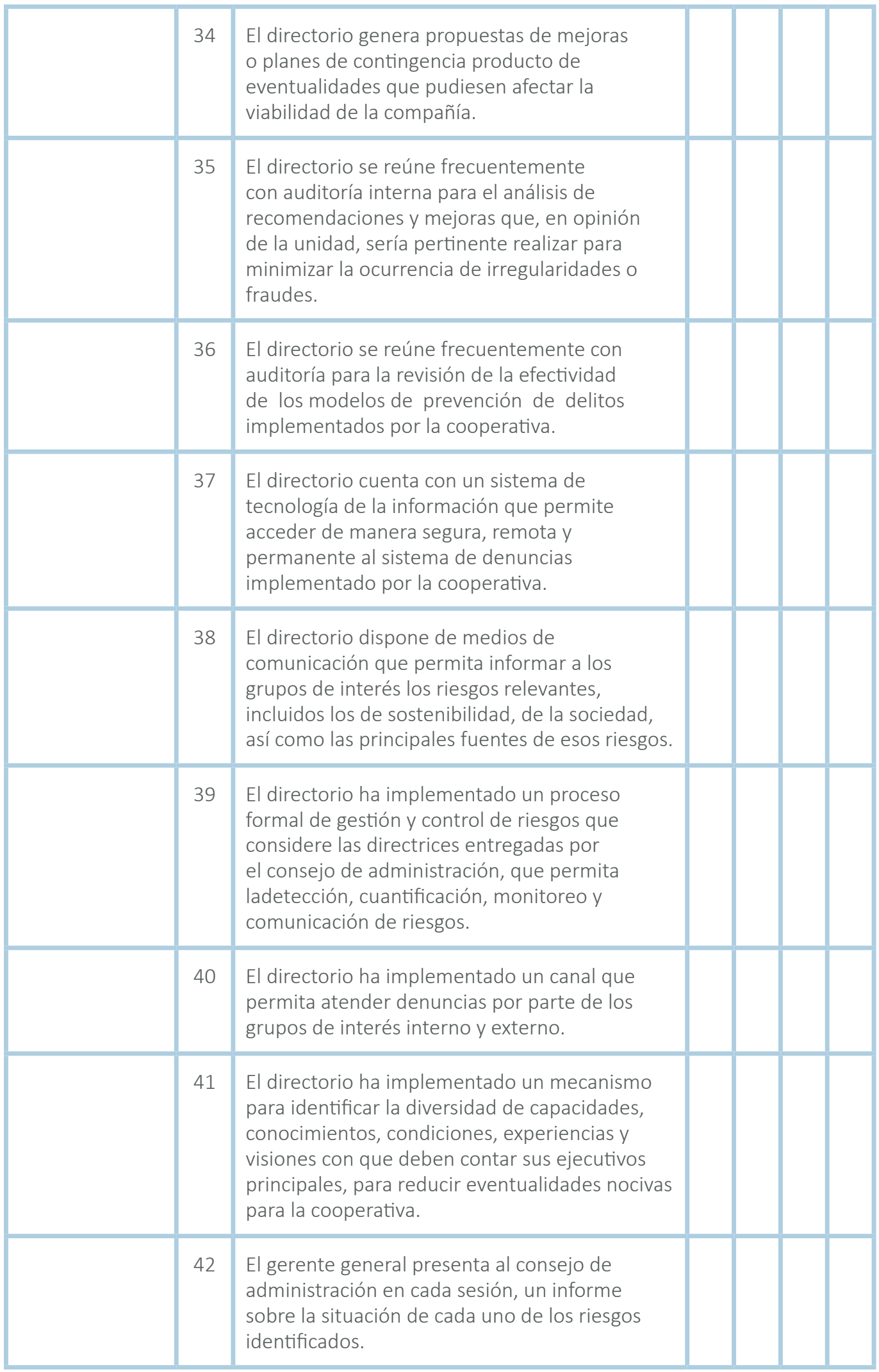




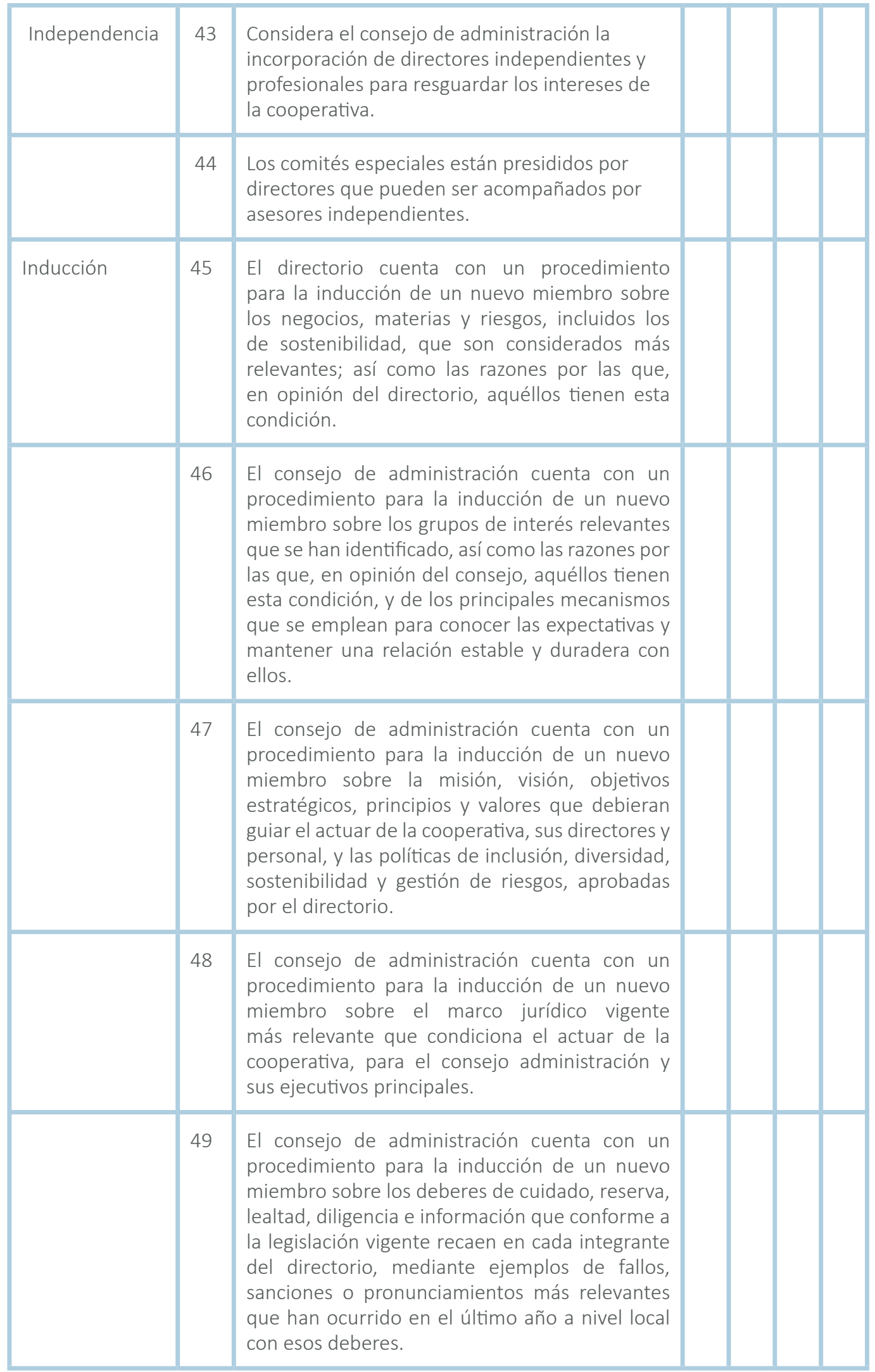




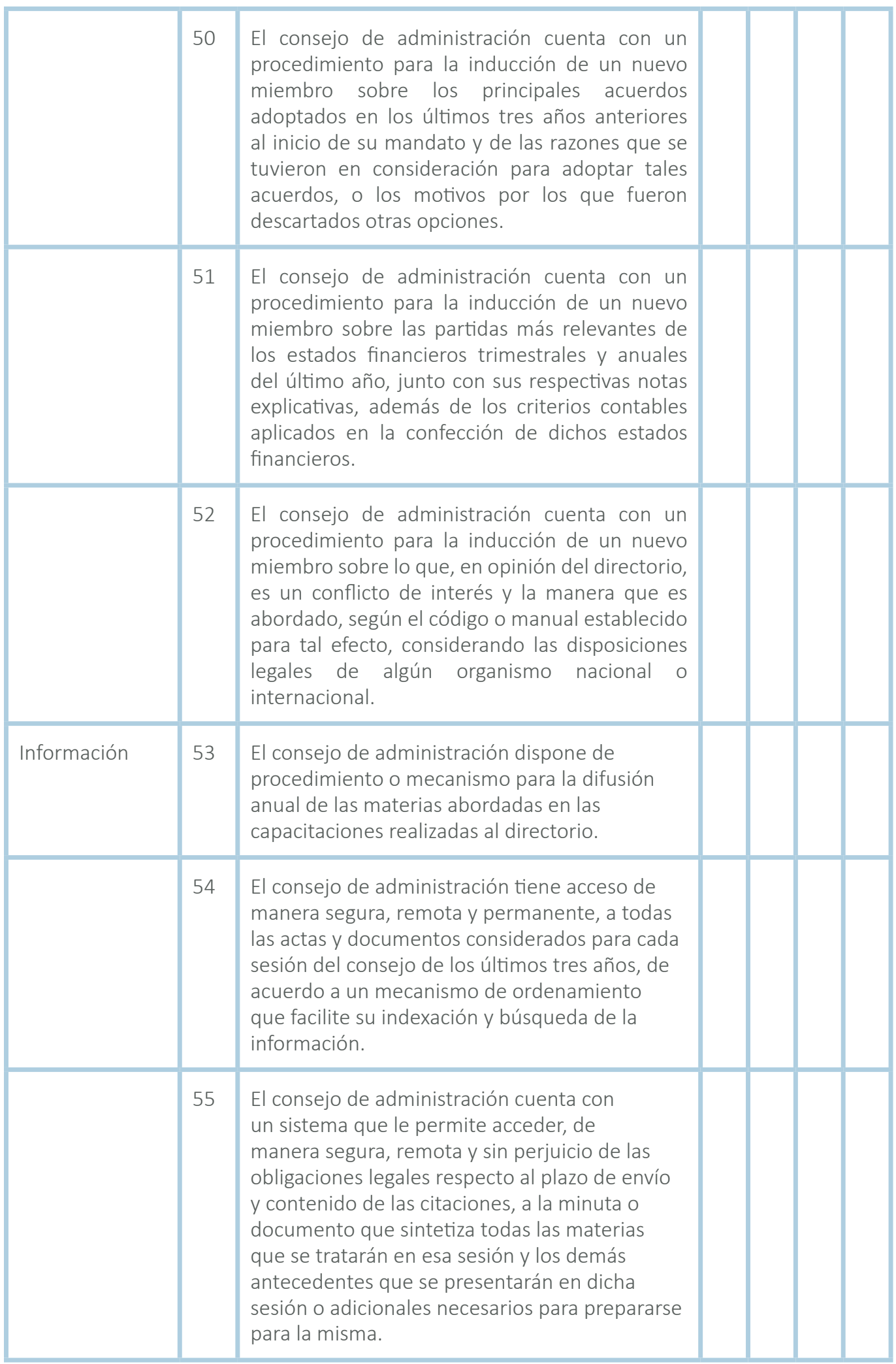




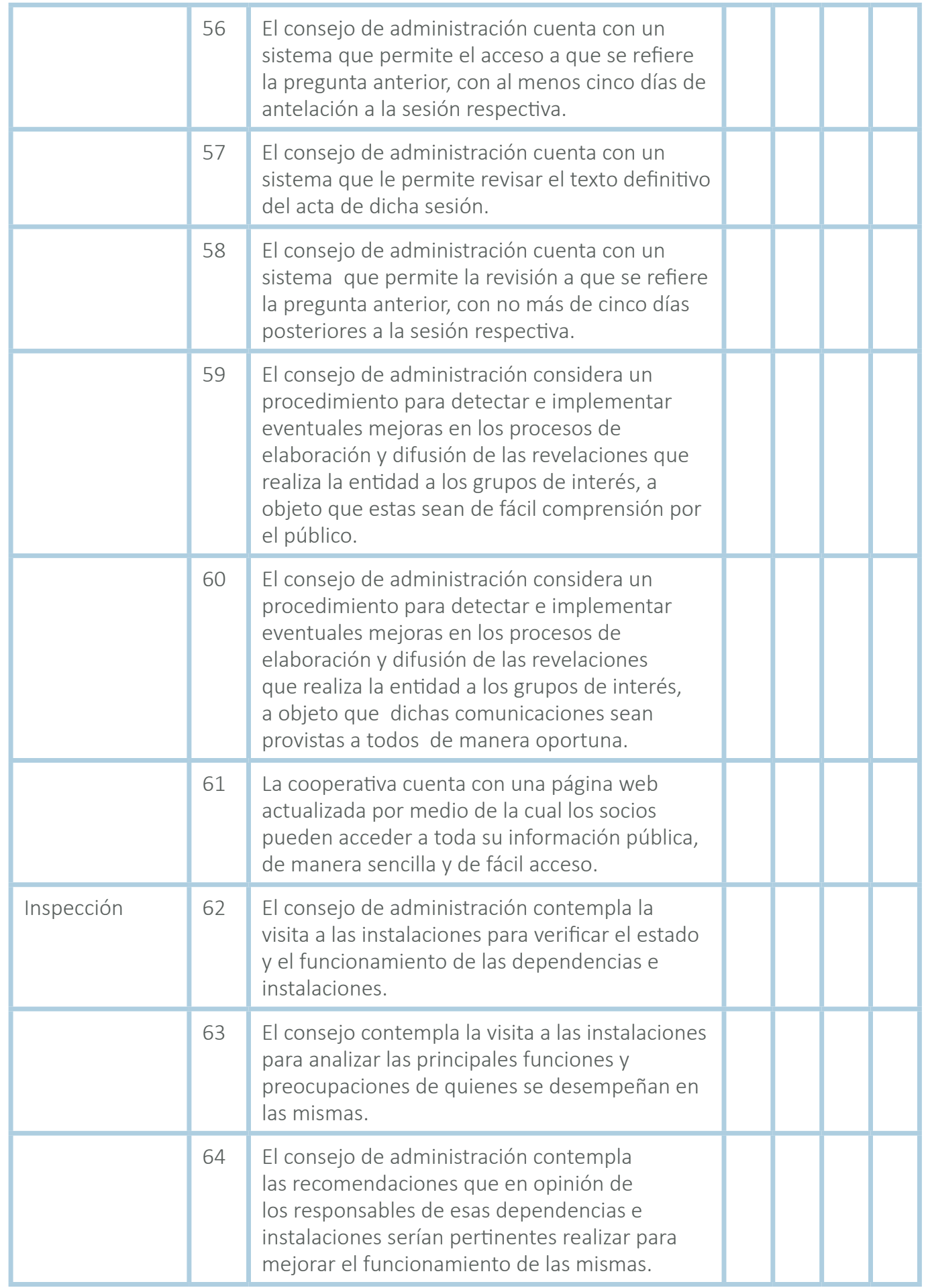




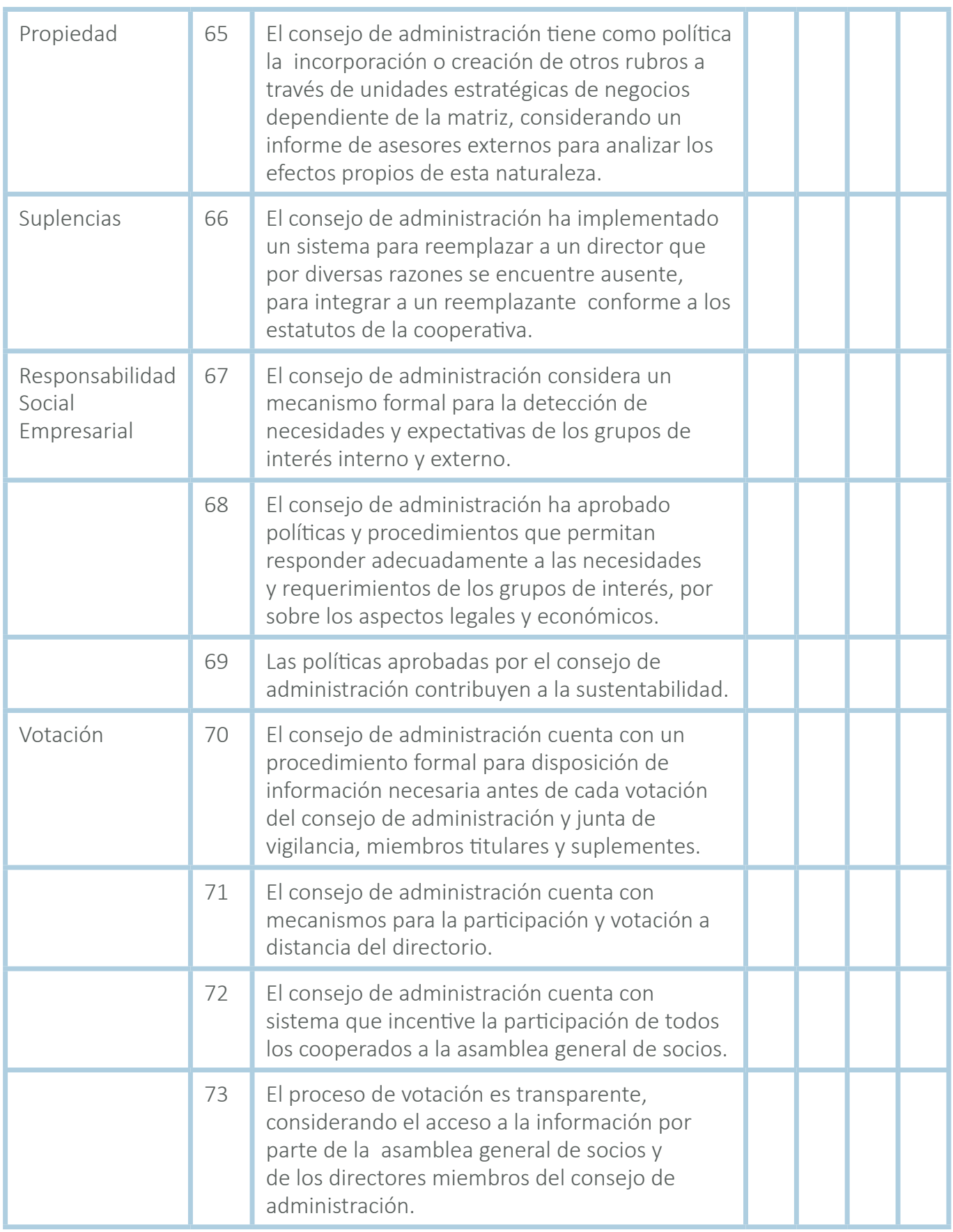

Fuente: Elaboración propia. 


\section{Como citar este artículo}

Severino-González, P., Medina, A., \& Lagos, J. (2018). Propuestas de buen gobierno corporativo para cooperativas eléctricas. Revista Pensamiento y Acción Interdisciplinaria, 4(1), 74-101. DOI: http://doi.org/10.29035/pai.4.1.74

\section{Dirección de correspondencia}

\section{Pedro Severino González}

Ingeniero Comercial. Magíster en Gestión de Empresas

Académico del Dpto. de Economía y Administración, Facultad de Ciencias

Sociales y Económicas, Universidad Católica del Maule, Talca, Chile.

Contacto:

pseverino@ucm.cl

Recibido: 23/07/2018

Aceptado: 26/09/2018 